\section{Is the increase in eltrombopag dose cause of myocardial infarction?}

\author{
Edip Can Özgünoğlu (D), Nermin Bayar (D), Şakir Arslan (D), \\ Muhammed Rıdvan Ersoysal (D), Rauf Avcı (D) \\ Department of Cardiology, University of Health Sciences, Antalya Training \\ and Research Hospital; Antalya-Turkey
}

\section{Introduction}

Immune thrombocytopenia (ITP) is an acquired disorder caused by immune-mediated attack, enhanced clearance, and insufficient compensatory production of platelets. Historically, ITP treatment strategies have suppressed platelet destruction with glucocorticoids, intravenous immune globulin (IVIG), cytotoxic agents, and splenectomy (1). Eltrombopag is an oral nonpeptide thrombopoietin receptor agonist (TPO-RA) approved for use in several countries for the treatment of ITP with insufficient response to corticosteroids, immunoglobulins, or splenectomy. In this study, we present a patient with ITP who developed recurrent myocardial infarction and intense thrombus in the stent after increasing the eltrombopag dose.

\section{Case Report}

A 52-year-old woman was admitted to our emergency room with chest pain. She had no traditional risk factors for coronary artery disease. We understood that the patient used eltrombopag as treatment for ITP; and 10 days ago, the dose of eltrombopag was increased from $50 \mathrm{mg} /$ day to $75 \mathrm{mg} /$ day owing to the platelet count being $9.000 / \mathrm{mm}^{3}$. Electrocardiography demonstrated acute anterior ST elevation myocardial infarction (STEMI). Acetylsalicylic acid (ASA $300 \mathrm{mg}$ ) and clopidogrel (600 $\mathrm{mg}$ ) were loaded, and coronary angiography was performed immediately. Angiography revealed $70 \%$ thrombotic occlusion in the proximal segment of the left anterior descending (LAD) artery. Unfractionated heparin $(70 \mathrm{IU} / \mathrm{kg})$ was administered, and a $3.0 \times 24 \mathrm{~mm}$ drug-eluting stent was implanted (Fig. 1). Her presenting platelet count was found to be $530,000 / \mathrm{mm}^{3}$. STEMI developed 10 days after the increase in eltrombopag dose. Therefore, drug-induced thrombosis was thought to be possible. Eltrombopag was discontinued with the recommendation of hematology. She was discharged on medical treatment (ASA 100 $\mathrm{mg}$, clopidogrel $75 \mathrm{mg}$, atorvastatin $40 \mathrm{mg}$, metoprolol succinate $50 \mathrm{mg}$, ramipril $5 \mathrm{mg}$ and pantoprazole).

Ten days later, the platelet count was $10,000 / \mathrm{mm}^{3}$. ASA was discontinued, and IVIG treatment was started. Clopidogrel was continued. Despite IVIG, severe thrombocytopenia continued, and eltrombopag $50 \mathrm{mg} /$ day was restarted. In the $10^{\text {th }}$ month, eltrombopag dose was increased to $75 \mathrm{mg} /$ day because the platelet count did not exceed $4000 / \mathrm{mm}^{3}$. Notably, 10 days after the dose increase, she presented to the emergency department

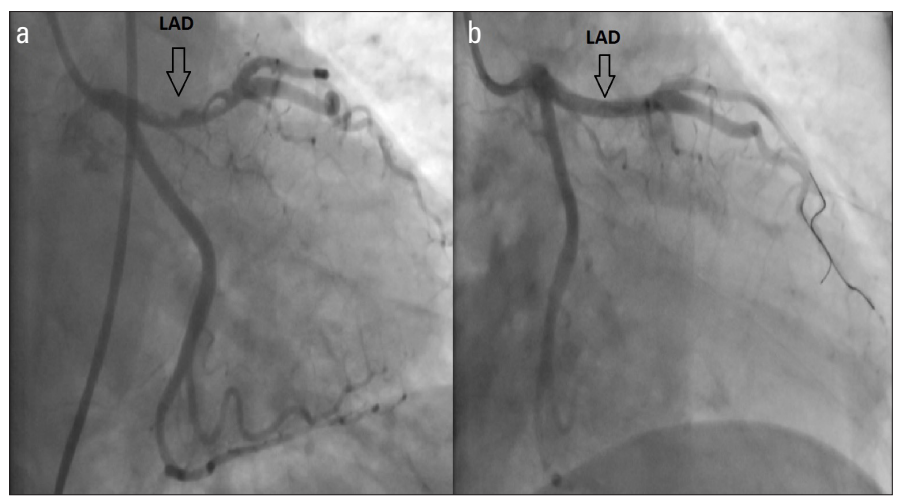

Figure 1. Coronary angiography images. (a) At presentation, acute anterior ST elevation. (b) After percutaneous coronary transluminal angioplasty was performed to the lesion in the proximal LAD LAD - left anterior descending artery

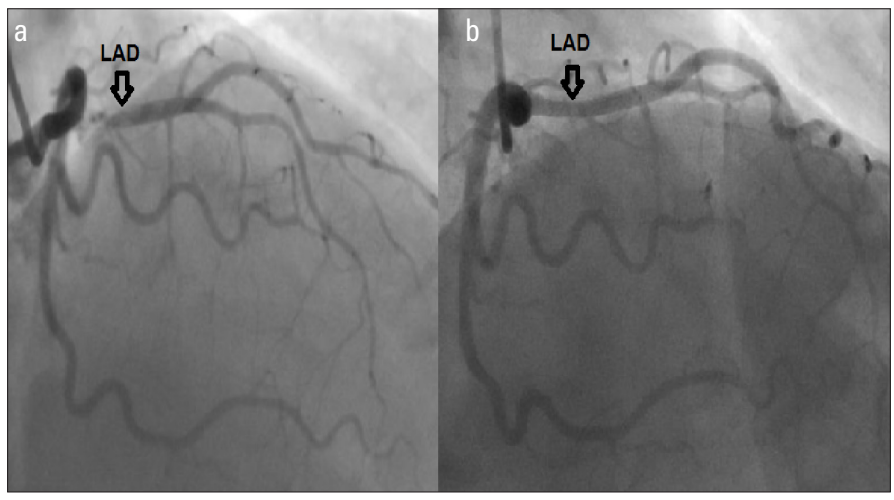

Figure 2. (a) Coronary angiography showed subtotal occlusion and intensive thrombosis at proximal portion of LAD in-stent. (b) Four days later, after abciximab infusion was administered, control coronary angiography revealed no thrombus and TIMI 3 flow

LAD - left anterior descending artery; TIMI 3 - thrombolysis in myocardial infarction 3

with chest pain. Angiography was performed again with the diagnosis of anterior STEMI. An intense thrombus appearance and subtotal occlusion in the LAD stent were seen on angiography. Platelet count was found to be $749,000 / \mathrm{mm}^{3}$. It was decided to administer abciximab infusion $(0.25 \mathrm{mg} / \mathrm{kg}$ IV bolus, then 0.125 $\mathrm{mcg} / \mathrm{kg} / \mathrm{min}$ intravenous infusion for 12 hours). Eltrombopag was ceased. Control angiography performed 4 days later showed that the thrombus had disappeared. Stent was not implanted (Fig. 2). No bleeding or ischemic event was observed during the 1-year follow-up.

\section{Discussion}

ITP is a disease that causes thrombocytopenia, and bleeding is common. Paradoxically, the risk of thromboembolism is also high. Increased risks of thromboembolic events are associated with larger platelets more adhesive to vascular surfaces, direct endothelial damage, and negative effects of therapy with steroids or intravenous immunoglobulin. More recent approaches have concentrated on enhancing platelet production with TPO- 
Ras (1). TPO-RAs are thought to increase platelet adhesion by increasing the number of platelets and their functions (2). Bussel et al. (3) have reported an overall thromboembolic event rate of $4.5 \%$ in patients with ITP treated with eltrombopag. In addition, cases of myocardial infarction have been reported in patients treated with eltrombopag (4-6). In our patient, the rapid and excessive increase in thrombocyte count after the eltrombopag dose was increased to $75 \mathrm{mg} /$ day may be responsible for the development of STEMI.

The aim of ITP treatment should be to reduce the risk of bleeding by keeping the platelet count in the range of $30,000 /$ $\mathrm{mm}^{3}-50,000 / \mathrm{mm}^{3}$ and to protect the patient from thrombosis by reducing the treatment when it exceeds $150,000 / \mathrm{mm}^{3}$ (7). There is no established treatment protocol for patients with ITP and with STEMI. There are case reports of different treatments, such as stent implantation, thrombolytic therapy, and the use of potent P2Y12 inhibitors $(8,9)$. Management of the bleedingthrombosis balance can be very challenging. It may be better to avoid stent implantation in patients with ITP because the response to dual antiplatelet therapy may differ from what is expected (9).

In our patient, we preferred to use glycoprotein $2 \mathrm{~B} / 3 \mathrm{~A}$ (GP2B/3A) inhibitor with close follow-up for bleeding. We chose this treatment option instead of placing a new stent. The absence of thrombus in the control angiography suggested that the treatment was successful. However, it should not be forgotten that there are also drug-induced ITP in patients associated with GP2B/3A inhibitors in the literature (10). Therefore, when administering this treatment, the benefit-harm ratio should be well evaluated, and individual decision should be made.

\section{Conclusion}

In patients using eltrombopag, close monitoring of the platelet count, especially during dose increase, is important. Individualized treatment should be planned considering the balance of bleeding and ischemia in patients with ITP presenting with acute coronary syndrome.

Informed consent: Written informed consent was obtained from patient.

Video 1. Coronary angiography showing subtotal occlusion and intensive thrombosis at the proximal portion of LAD in-stent

LAD - left anterior descending artery
Video 2. Four days later, after abciximab infusion was administered, control coronary angiography revealed no thrombus and TIMI 3 flow

TIMI 3 - thrombolysis in myocardial infarction 3

\section{References}

1. Neunert C, Lim W, Crowther M, Cohen A, Solberg L Jr, Crowther MA; American Society of Hematology. The American Society of Hematology 2011 evidence-based practice guideline for immune thrombocytopenia. Blood 2011; 117: 4190-207. [Crossref]

2. Haselboeck J, Kaider A, Pabinger I, Panzer S. Function of eltrombopag-induced platelets compared to platelets from control patients with immune thrombocytopenia. Thromb Haemost 2013; 109: 676-83. [Crossref]

3. Bussel JB, Cheng G, Saleh MN, Mayer B, Vasey SY, Brainsky A. Incidence of Thromboembolic Events Across Eltrombopag Clinical Trials In Chronic Immune Thrombocytopenia (ITP). Blood 2010; 116: A70. [Crossref]

4. Teichman J, Taher A, Hashi A, Bagai A, Sholzberg M. A sticky situation: myocardial infarction in a young woman with immune thrombocytopenia on eltrombopag and a history of mediastinal radiation. J Thromb Thrombolysis 2018; 45: 192-5. [Crossref]

5. Sert S, Özdil H, Sünbül M. Acute Myocardial Infarction Due to Eltrombopag Therapy in a Patient with Immune Thrombocytopenic Purpura. Turk J Haematol 2017; 34: 107-8. [Crossref]

6. Gunes H, Kivrak T. Eltrombopag Induced Thrombosis: A Case with Acute Myocardial Infarction. Curr Drug Saf 2016; 11: 174-6. [Crossref]

7. Andic N, Gunduz E, Akay OM, Şahin D, Teke HÜ. Cardiac and pulmonary thrombosis during multidrug treatment in an idiopathic thrombocytopenic purpura patient. Platelets 2014; 25: 69-70. [Crossref]

8. Koklu E, Kus G, Yuksel I0, Kucukseymen S, Arslan S. Successful thrombolytic therapy for ST-elevation acute myocardial infarction in a patient with immune thrombocytopenic purpura. Am J Emerg Med 2016; 34: 345.e1-3. [Crossref]

9. Satoh T, Saotome M, Suwa K, Ohtani H, Nagata $Y$, Ono T, et al. Recurrent Coronary Thrombus in a Patient with Chronic Immune Thrombocytopenia with Treatment Using Eltrombopag. Case Rep Cardiol 2019; 2019: 2756319. [Crossref]

10. Garbe E, Andersohn F, Bronder E, Salama A, Klimpel A, Thomae M, et al. Drug-induced immune thrombocytopaenia: results from the Berlin Case-Control Surveillance Study. Eur J Clin Pharmacol 2012; 68: 821-32. [Crossref]

Address for Correspondence: Dr. Edip Can Özgünoğlu,

Antalya Eğitim ve Araştırma Hastanesi, Kardiyoloji Kliniği, Antalya-Türkiye Phone: +90 5454454370

E-mail: edipcanozgunoglu@gmail.com

CCopyright 2021 by Turkish Society of Cardiology -

Available online at www.anatoljcardiol.com

DOI:10.5152/AnatolJCardiol.2021.45605 